\section{CLOSTRIDIUM DIFFICILE}

\section{Improvement targets for Cdifficilemust be valid}

We have identified a potentially distorting factor in the delivery of reductions in Clostridium difficile rates. ${ }^{1}$ A letter sent to chief executives of trusts, primary care trusts, and strategic health authorities in England in December 2006 stated that the forthcoming NHS operating framework for 2007-8 and the NHS contract require primary care trusts to agree a local target with their acute hospital providers for a significant reduction in $C$ difficile infections. ${ }^{2}$ The target is expected to be "locally appropriate" and based on "current performance." A reduction of at least 25\% was suggested for trusts with a rate greater than four cases per 1000 bed days (in people over 65), while maintenance of the current rate would be an appropriate target for trusts with a rate of one per 1000 bed days or lower.

The West Midlands Strategic Health Authority initially imposed indicative targets for all acute trusts to negotiate with primary care trusts in the region, based not on the most recent data but on the average of 2004 and 2005 figures. The number of $C$ difficile infections has increased by over $25 \%$ across the West Midlands during 2006 compared

\section{Strategic health authority improvement targets for} West Midlands acute trusts to reduce $C$ difficile rates

\begin{tabular}{|c|c|c|c|c|}
\hline Trust & $\begin{array}{l}\text { Average rate } \\
\text { for } 2004-5^{\star}\end{array}$ & $\begin{array}{c}\text { Improvement } \\
\text { target } \ddagger\end{array}$ & $\begin{array}{c}\text { Rate for } \\
2006\end{array}$ & $\begin{array}{l}\text { Improvement } \\
\text { required } t\end{array}$ \\
\hline A & 3.05 & 18.75 & 3.55 & 30.14 \\
\hline B & 2.75 & 18.75 & 2.90 & 23.10 \\
\hline C & 4.22 & 25.00 & 5.17 & 38.68 \\
\hline D & 2.33 & 12.50 & 3.70 & 44.86 \\
\hline $\mathrm{E}$ & 2.60 & 18.75 & 2.88 & 26.74 \\
\hline $\mathrm{F}$ & 4.55 & 25.00 & 4.16 & 18.03 \\
\hline G & 1.13 & 6.25 & 3.44 & 69.19 \\
\hline $\mathrm{H}$ & 2.76 & 18.75 & 2.75 & 18.55 \\
\hline 1 & 2.74 & 18.75 & 5.21 & 57.39 \\
\hline$J$ & 1.86 & 12.50 & 4.02 & 59.45 \\
\hline $\mathrm{K}$ & 2.21 & 12.50 & 2.88 & 33.00 \\
\hline $\mathrm{L}$ & 1.46 & 12.50 & 1.76 & 27.27 \\
\hline M & 1.34 & 12.50 & 2.16 & 45.83 \\
\hline $\mathrm{N}$ & 3.04 & 18.75 & 2.62 & 5.73 \\
\hline 0 & 1.36 & 12.50 & 3.03 & 60.72 \\
\hline$P$ & 3.47 & 18.75 & 3.30 & 14.55 \\
\hline
\end{tabular}

with this figure. Therefore the reductions imposed are in many cases far in excess of the targets suggested in the letter from the Department of Health, or as stated by the strategic health authority (table). Since it was explained to the authority that these targets are inappropriate, it has agreed to recalculate them.

When targets for methicillin resistant Staphylococcus aureus (MRSA) bacteraemia were set, they were imposed centrally and have been non-negotiable, despite statistical evidence showing that the methods used were invalid. ${ }^{3}$ The MRSA targets will not be met; if $C$ difficile rates are to be reduced targets must be potentially attainable. Although we are in favour of targets that increase the focus on reducing hospital acquired infections, we draw attention to the importance of using contemporaneous baseline data when trying to control a rapidly expanding problem. Infection control teams in trusts should ensure they are aiming at the right target, which should be scientifically valid.

M A Cooper director, infection prevention and control, Royal Wolverhampton Hospitals NHS Trust, Department of Microbiology, New Cross Hospital, Wolverhampton WV10 OQP

P M Hawkey consultant medical microbiologist, West Midlands Public Health Laboratory, Birmingham Heart of England NHS Trust, Birmingham B95SS

peter.hawkey@heartofengland.nhs.uk

On behalf of the West Midlands Microbiologists Group

\section{Competing interests: None declared.}

1 Green D. Management of Clostridium difficile in NHS trusts. BMJ 2006;332:238. doi: 10.1136/ bmj.332.7535.238

2 Dear colleague letter to chief executives of trusts, PCTS and SHAs dated 7 December 2006. www.dh.gov. uk/en/Publicationsandstatistics/Lettersandcirculars/ Dearcolleagueletters/DH_063090

3 Spiegelhalter DJ. Problems in assessing rates of infection with methicillin resistant Staphylococcus aureus. BMJ 2005;331:1013-5.

\section{TRANSPARENCY IN NICE}

\section{Let's open whole process of cost effective modelling}

The National Institute for Health and Clinical Excellence (NICE) needs to go much further than allowing access to its modelling data. ${ }^{1}$ The whole cost effectiveness modelling process needs to be opened up to involvement by all stakeholders, and inspection by the public, as it happens. The independent group should be contracted to develop the one and only model that NICE will consider in its appraisal, and it should do so in full and continuous collaboration with all registered stakeholders and interested parties who sign up to the NICE guidelines. The model will be run with any alternative parameters suggested by various parties and the alternative results (along with their evidential basis) submitted to the appraisal committee in a single report. No subsequent questioning of, or submissions regarding, the model structure, the results, or the underlying principles would be accepted in the context of any particular case.

Jack Dowie emeritus professor of health impact analysis, London School of Hygiene and Tropical Medicine, London WC1E 7HT

jack.dowie@lshtm.ac.uk

Competing interests: None declared.

1 Maynard A. Transparency in health technology assessments. BMJ 2007;334:594-5. (24 March.)

\section{GLOBAL PARTNERSHIP}

\section{UK doctors are already put off by} changes in training

We direct collaborative programmes of medical research in low income or middle income countries, with support from UK and local institutions. Each site has a team of local and international doctors, scientists, and support staff. We use high quality research to help to understand local health problems and find ways to address these problems. We provide opportunities for local professionals to work with colleagues from the UK and elsewhere, thereby gaining experience to deal with their own problems in their own setting. UK doctors play a crucial part in each of these programmes. ${ }^{1}$ They contribute to the work, gain a wider perspective on international health problems, see a large range of disease problems, learn how to be resourceful, and contribute to advances against some of the world's commonest health problems. Such experience is of great value not only in the host country but for individuals' development as future NHS professionals. It is also crucial to the international perspective commended in the Crisp report. $^{2}$

Most UK doctors spending time in one of our research programmes wish to return to a career in the United Kingdom. If this re-entry is made difficult or impossible 
they are unlikely to come abroad in the first place. The individual, the NHS, and the international community would all be impoverished as a result.

Modernising Medical Careers (MMC) as currently formulated is likely to make it difficult for a young doctor to spend time working in a developing country. A revised MMC should include mechanisms that not only permit but strongly encourage UK doctors to work in a developing country at some stage during clinical specialist training.

Malcolm Molyneux Malawi-Liverpool Wellcome Trust Clinical Research Programme, Box 30096, Blantyre 3, Malawi directormmolyneux@malawi.net

And Kevin Marsh, Nicholas White, Jeremy Farrar, Neil French, Nick Day, and Sarah Rowland-Jones representing Kenya Medical Research Institute (KEMRI)-

Wellcome Trust Programme, Kenya; Wellcome Trust South-East Asian Tropical Medicine Research Programmes; Hospital for

Tropical Diseases Wellcome Trust Major Overseas Programme, Ho Chi Minh City, Vietnam; Karonga Prevention Study, Malawi; Wellcome Trust-Mahidol University-Oxford Tropical Medicine Research Programme, Thailand; and MRC Laboratories, the Gambia.

\section{Competing interests: None declared.}

1 Whitty CJM, Doull L, Nadjm B. Global health partnerships. BMJ 2007;334:595-6. (24 March.)

2 Global health partnerships: the UK contribution to health in developing countries [Crisp report]. 2007. www. dh.gov.uk/en/Publicationsandstatistics/Publications/ PublicationsPolicyAndGuidance/DH 065374.

\section{NOT EVEN A DOG'S LIFE}

\section{It's not a question of dogs or babies}

Veterinary medicine is, for the most part, a form of private medicine. ${ }^{1}$ Money that animal owners elect to spend on promoting the health and welfare of their animals does not generally represent funds that would otherwise be used to promote human welfare, at home or abroad. It is money that might otherwise be spent enlarging carbon footprints on foreign holidays, upgrading cars to newer versions, filling wardrobes or antique shelves, carrying out home improvements. In that sense, choosing to spend money on promoting the health and welfare of other sentient beings is surely not quite so deplorable and shallow as Towey makes out.

Poor countries are denied advanced medical treatment not because of its use in Western pet veterinary medicine but because of macroeconomics and global politics.

Other important questions need to be debated: the ethical boundaries of animal treatment; what is done, and for whom, and when; and when treatment should stop-an animal welfare issue; the ethics of pet keeping itself; and so on. Further, it should not be forgotten that modern medicine has used other animal species to a great extent in terms of research and experimentation. When it is in their interests, animals should also benefit from this. Ghandi said that you could judge a nation by the way it treated its animals.

Andrew A Gardiner veterinarian, Edinburgh EH89RF andrew@wag-wag.freeserve.co.uk

Competing interests: AAG is a dog owner, veterinary surgeon, and also concerned with human welfare.

1 Towey R. Not even a dog's life. BMJ 2007;334:638. (24 March.)

\section{Wish I was a celebrity's pet}

Towey may call the gap in the quality of medical care between the developed and developing worlds obscenity or racism, but most of the Nepalese people who cannot afford the cost of treatment call it fate. ${ }^{1}$

Medical care in Nepal will, perhaps, continue to be like this for many years to come. Most of us are adapted to this system. We do not attribute it to developed countries but to the inadequacy of our own government.

It is true that many "Western" dogs are more privileged than the human population here in Nepal in terms of medical care. But this disparity does not exist in medical care alone. It is just a part of the total economic gap between the developing and developed world.

Siddhartha Yadav student, Maharajgunj Campus, Institute of Medicine, Kathmandu, Nepal siddhartha@iom.edu.np

\section{Competing interests: None declared. \\ 1 Towey R. Not even a dog's life. BMJ 2007;334:638. (24 March.)}

\section{HYPERTHYROIDISM}

\section{Total thyroidectomy is best operation for thyrotoxicosis}

We were concerned by the statement that subtotal thyroidectomy in experienced hands guarantees patients the longest existence without taking drugs. ${ }^{1}$ This implies that subtotal thyroidectomy is the operation of choice in thyrotoxicosis. We believe that is not the case, firstly, because the operation of subtotal thyroidectomy is not clearly defined: the amount of thyroid tissue left behind varies from centre to centre. Secondly, there is a small but definite occurrence rate of thyroid cancer in both Graves' disease and toxic multinodular goitre $4 \%$ in our series of 100 total thyroidectomies (all pathologies) for thyrotoxicosis ${ }^{2}$ ). Thirdly, because there is a notable rate of both postoperative hyperthyroidism and hypothyroidism after subtotal thyroidectomy, each outcome effectively defeats the point of the operation type. ${ }^{3}{ }^{4}$

Total thyroidectomy is the only appropriate procedure for the surgical management of thyrotoxicosis in the United Kingdom.
It guarantees cure, and, although it also guarantees hypothyroidism, thyroxine replacement treatment is far more predictable as the operation is clearly defined.

RJames A England consultant ear, nose, and throat surgeon Hull Royal Infirmary, Hull HU32PZ RJAEATHOME@aol.com

Steve Atkin professor of endocrinology

Competing interests: None declared.

1 Toft A, Sandeep TC. Radioiodine treatment of hyperthyroidism. BMJ 2007;334:483-4. (10 March.)

2 England RJA, Kamath MB, Jabreel A, Dunne G, Atkin SL. How we do it: surgery should be considered equally with I131 and thionamide treatment as first line therapy for thyrotoxicosis. Clin Otol 2006;31:160-2.

3 Hedley AJ, Bewsher PD, Jones SJ, Khir AS, Clements P, Matheson NA, et al. Late onset hypothyroidism after subtotal thyroidectomy for hyperthyroidism: implications for long term follow-up. Br J Surg 1983;70:740-3.

4 Lal G, Ituarte P, Kebebew E, Siperstein A, Duh QY, Clark $\mathrm{OH}$. Should total thyroidectomy become the preferred procedure for the surgical management of Graves disease? Thyroid 2005;15:569-74.

\section{IMPACT FACTORS}

\section{The dark side}

Martyn's tongue in cheek advice to the new editor of a prestigious-if fictionaljournal is to raise the impact factor by various measures including "resisting any sympathy when a paper is submitted on an unfashionable condition such as deafness." As a psychiatrist working with deaf sign language users I was delighted to see, at last, a mention of deafness in a prestigious-and non-fictional-journal.

My team's attempts at getting articles published in mainstream journals have been met with responses such as "not of general interest" and "there is a misspelling with Deaf spelt with a capital D" (this is the recognised name for culturally deaf sign language users). My personal favourite is a review of a paper on adapting an instrument into British Sign Language: "I would expect that particularly among deaf people an interview poses difficulties because of the sensory handicap, and the most logical choice would be to use or produce a (suitable) written format"-that Deaf people are "functionally illiterate" was spelt out in the introduction: do reviewers read introductions?

Learning disability psychiatrists have overcome this by developing their own journals. Deafness is quickly following suit. This pushes the evidence base on psychiatry in disability out of the mainstream journals at a time when policy is pushing the care of patients with learning disability and deafness into mainstream services.

Helen E J Miller consultant psychiatrist, National Deaf Service, LondonSW129HW helen.miller@swlstg-tr.nhs.uk

Competing interests: None declared.

1 Martyn C. Advice to a new editor. BMJ 2007;334:586. (17 March.) 